\title{
A INFLUÊNCIA DA PUBLICIDADE NO CONSUMO EXACERBADO
}

\author{
Hertha Urquiza Baracho ${ }^{1}$ \\ Soraya Braga de Sousa Dantas ${ }^{2}$
}

RESUMO

O presente artigo objetiva tratar da influência da publicidade no comportamento das pessoas quanto ao consumo em todas as fases da vida. Elenca a proteção legislativa voltada ao consumidor, além de relatar as consequências decorrentes do consumismo. Assim, a educação financeira seria a melhor solução para evitar o superendividamento que atualmente representa um grande problema na vida dos brasileiros. A pesquisa é documental e bibliográfica com o uso do método de abordagem dedutivo.

PALAVRAS-CHAVE: Publicidade. Consumismo. Proteção Legislativa. Superendividamento.

\section{THE INFLUENCE OF ADVERTISING AT EXACERBATED CONSUMPTION}

\begin{abstract}
The present article aims to deal with the influence of advertising on people's behavior regarding consumption in all phases of life. It lays down legislative protection aimed at the consumer, as well as reporting the consequences of consumerism. Thus, financial education would be the best solution to avoid the over-indebtedness that currently represents a great problem in the life of Brazilians. The research is documentary and bibliographical with the use of the method of deductive approach.
\end{abstract}

KEYWORDS: Advertising. Consumerism. Legislative Protection. Super Indebtedness.

\section{INTRODUÇÃO}

Com a implantação das grandes indústrias e o aumento da produção, houve a necessidade de estimular o consumo dos bens produzidos. O principal instrumento para tal fim foi a prática da publicidade. Esta foi se transformando ao longo do tempo, e o que era apenas de caráter informativo tornou-se cada vez mais complexo, aperfeiçoando-se no sentido de influenciar e até mesmo impor ao consumidor determinado produto ou serviço. A disputa pelo controle do mercado e a concorrência desenfreada fizeram com que a publicidade se tornasse cada vez mais agressiva e voltada para geração de lucros a todo custo. Não se tratava

\footnotetext{
${ }^{1}$ Pós-Doutorado na Università degli Studi di Firenzi, UNIFI, na área das Ciências Sociais Aplicadas. Doutora em Direito do Estado (Área de concentração Direito Constitucional) pela PUC/SP. Mestre em Direito do Estado (Área de concentração Direito Constitucional) pela PUC/SP. Professora do Centro Universitário de João Pessoa UNIPÊ. Coordenadora do Grupo de Pesquisa: Relações Empresariais: função social e responsabilidade Social das Empresas.

2 Bacharel em Direito pela UNIPÊ. Adovada (OAB 17630). Especialista em Ciências Criminais Anhanguera/SP. Mestranda em Direito e Desenvolvimento Sustentável - PPGD/UNIPE
} 
mais de sugerir, mas de convencer. E com o objetivo de estancar tais práticas surgiu a legislação, tendo o intuito de regular este tipo de atividade e com isto proteger a figura do consumidor.

No sistema capitalista em que vivemos, nos deparamos com algo dotado de extrema complexidade, que envolve a sociedade de uma forma encantadora e ao mesmo tempo dominadora, a chamada publicidade. Este instrumento possui um papel fundamental para as empresas, pois através da publicidade, os produtos são divulgados e consequentemente comercializados em larga escala.

Ocorre que o principal objetivo da publicidade é atrair a atenção da população e atingir o maior número de vendas. Seja adulto, adolescente ou criança, não importa, o lucro está sempre em primeiro lugar.

Várias são as consequências oriundas desta magia: o consumo desenfreado, o superendividamento, ou, como Zigmunt Bauman (2008) menciona, trata-se da eterna busca da felicidade, de um produto novo, capaz de deixar o consumidor encantado e convicto de que se não comprá-lo, será infeliz, ultrapassado ou desprezado socialmente. Eis que, os consumidores movem a economia e por isso são assediados de tal forma que o direito tem o papel de protegê-los.

O presente artigo tem por objetivo discutir sobre a publicidade, sua influência sobre o consumidor e o que motiva o comportamento deste. Propõe uma reflexão acerca da maneira como os publicitários estão lidando com a sociedade, posto que, perdem o bom senso quando o assunto é lucro. Além disso, expõe algumas consequências provenientes do consumismo. Neste sentido, doutrinadores colocam a figura do consumidor como um ser vulnerável e hipossuficiente, que necessita de proteção jurídica. Para que esta pesquisa alcance seu objetivo, foram estabelecidos alguns procedimentos metodológicos a fim de conferir um caráter científico ao artigo, com a utilização da técnica de pesquisa de documentação indireta, ou seja, pesquisa documental e bibliográfica. A vertente metodológica será de natureza qualitativa, com o emprego do método de abordagem dedutivo.

\section{PUBLICIDADE: CONCEITO E CONSIDERAÇÕES IMPORTANTES}

A oferta de um bem ou serviço se dá por meio da publicidade. Esta demonstra ser a principal ferramenta utilizada pelas grandes e pequenas empresas que visam convencer, ou melhor, seduzir o consumidor levando-o ao consumo por vezes desenfreado.

Assim, João Batista de Almeida (2008, p. 116) explica em sua obra o conceito de 
publicidade:

No contexto das práticas comerciais, publicidade é uma forma de veiculação da oferta, sujeitando-se, como tal, aos mesmos requisitos e regime de responsabilização (arts. 30, 35, 36, 37 e 38). Define-a o Código Brasileiro de Auto-Regulamentação Publicitária como "toda atividade destinada a estimular o consumo de bens e serviços, bem como promover instituições, conceitos e ideias" (art. 8). Na mesma linha, é conceituada no Decreto n. 57.690/66, como "qualquer forma remunerada de difusão de ideias, mercadorias, produtos ou serviços por parte de um anunciante identificado." (art.2).

É muito comum confundir publicidade com propaganda, principalmente pelo fato de ambas atuarem no convencimento das pessoas, no entanto, são instrumentos que possuem significados bem distintos. Para uma melhor compreensão vale destacar o objetivo de cada um destes instrumentos através do entendimento de Antônio Herman de Vasconcelos e Benjamin (2001, p. 270):

Não se confundem publicidade e propaganda, embora, no dia-a-dia do mercado, os dois termos sejam utilizados um pelo outro. A publicidade tem um objetivo comercial, enquanto a propaganda visa um fim ideológico, religioso, filosófico, político econômico ou social. Fora isso, a publicidade, além de paga, identifica seu patrocinador, o que nem sempre ocorre com a propaganda.

Desta forma, tanto a publicidade como a propaganda têm como objetivo propagar informações direcionadas ao consumidor de forma a convencê-lo de que determinado serviço ou produto é essencial em sua vida. No entanto, a principal diferença entre esses dois institutos se dá pelo fato de a publicidade estar atrelada a uma atividade comercial, ou seja, possui um propósito econômico; já a propaganda é toda atividade que divulga ideias ou ideologias, voltada para conteúdos informativos.

Lucia Ancona Lopez de Magalhães Dias afirma que a legislação brasileira parece fazer confusão em relação ao emprego dos referidos conceitos. A Constituição Federal, por exemplo, utilizou, no $\S 4^{\circ}$ do art.220 da CF, a expressão "propaganda comercial" ao se referir à publicidade comercial. O Código de Defesa do Consumidor, quando regulamenta nos arts.56, XII, e 60 a imposição da "contrapropaganda" na verdade está se referindo à publicidade enganosa ou abusiva.(DIAS, 2018, p.28).

A partir do século XX, com o avanço dos meios de comunicação e o aparecimento da sociedade de massa, a publicidade que antes era informativa no sentido de se contentar em apresentar o produto ou o serviço à população e indicar o local onde poderia ser adquirido, passou a representar um importante instrumento de concorrência entre as empresas que passaram a utilizar instrumentos de persuasão, com o objetivo de atrair consumidores. A comunicação publicitária aperfeiçoa-se no sentido de utilizar linguagem convincente e atrativa. 
Atualmente, diante de qualquer comunicação publicitária o consumidor deve ficar atento, pois ela certamente não é meramente informativa e neutra, ela tem a função de persuadir, de convencer, de sugerir, o seu objetivo é fazer a sociedade agir no sentido de comprar o produto ou serviço de sua marca e não da marca concorrente.

\subsection{PROTEÇÃO LEGISLATIVA}

Com o intuito de proteger a parte mais fraca da relação de consumo, a Lei $\mathrm{n}^{\circ}$. 8.078, o Código de Defesa do Consumidor (CDC), apresenta uma seção específica que trata da publicidade, determinando os tipos de Publicidade que podem ser considerados prejudiciais ao consumidor no contexto das práticas comerciais. No artigo 36 o CDC proíbe a publicidade não identificada ou de difícil identificação para evitar a publicidade disfarçada. Já no artigo

37 coibe a publicidade enganosa e a publicidade abusiva. Destacam-se os seguintes parágrafos do artigo 37 do referido código:

$\S 1^{\circ}$ É enganosa qualquer modalidade de informação ou comunicação de caráter publicitário, inteira ou parcialmente falsa, ou, por qualquer outro modo, mesmo por omissão, capaz de induzir em erro o consumidor a respeito da natureza, características, qualidade, quantidade, propriedades, origem, preço e quaisquer outros dados sobre produtos e serviços.

$\S 2^{\circ}$ É abusiva, dentre outras a publicidade discriminatória de qualquer natureza, a que incite à violência, explore o medo ou a superstição, se aproveite da deficiência de julgamento e experiência da criança, desrespeita valores ambientais, ou que seja capaz de induzir o consumidor a se comportar de forma prejudicial ou perigosa à sua saúde ou segurança.

$\S 3^{\circ}$ Para os efeitos deste Código, a publicidade é enganosa por omissão quando deixar de informar sobre dado essencial do produto ou serviço.

Quanto à defesa do consumidor diante da Constituição Federal de 1988 (CF), foi posta como um direito e uma garantia fundamental: "o Estado promoverá, na forma da lei, a defesa do consumidor"(art. $\left.5^{\circ}, \mathrm{XXXII}\right)$, tornando-se um direito fundamental. Observa-se esta proteção também no art. 24, VIII, ao narrar a competência legislativa concorrente à União, Estados e Distrito Federal com relação à responsabilidade pelos danos que por ventura o consumidor venha a sofrer.

No entanto, ainda surge uma nova discussão acerca da publicidade quando ela se vale do meio virtual para expandir o comércio e com isto atingir o maior número de consumidores. De acordo com Otávio T. de Carvalho Júnior (2013, p. 54):

O CDC buscou coibir de maneira eficiente as práticas comerciais abusivas contra o consumidor, explicitando princípios e regras que regulam a matéria e instituindo meios para garantir eficácia de suas prescrições, anulando ou pelo menos minimizando os efeitos negativos dos abusos perpetrados nessa seara. A legislação se defronta hoje com novos desafios, entre eles a amplitude do comércio eletrônico, que instigam a adoção de novas normas e a adequação das 
já existentes [...].

Com relação a esta nova realidade, em que a informação transita com uma rapidez extraordinária, a publicidade bem utiliza-se de novos meios tecnológicos para alcançar o consumidor e envolvê-lo em um mundo de fantasia em que a busca pela felicidade termina por transformá-lo em uma mercadoria a ser reciclada a todo instante para ocupar a prateleira da vida.

O CDC preocupou-se em proteger a figura do consumidor por meio de princípios expostos ao longo dos seus dispositivos tencionando amparar a parte mais fraca da relação de consumo. Veem-se, portanto, alguns exemplos destes princípios: o artigo 36 elenca o princípio da identificação da publicidade, e neste mesmo artigo, no seu parágrafo único, destaca-se o princípio da transparência publicitária em que o consumidor interessado passa a ter acesso aos dados técnicos e científicos dos produtos ofertados; os artigos 30 e 35 tratam da vinculação contratual da publicidade; o artigo 37, em seu parágrafo primeiro, ressalta o princípio da veracidade ao repudiar qualquer modalidade de informação enganosa que possa induzir o consumidor ao erro com relação aos produtos comercializados; ainda no artigo 37, parágrafo segundo, aponta-se para o princípio da não-abusividade da publicidade ao abominar qualquer publicidade que possua natureza discriminatória; pode-se citar também o artigo 38 que versa sobre o princípio da inversão do ônus da prova quando remete ao patrocinador o dever de provar a veracidade, corrigir a informação ou comunicação publicitária; cita-se aqui também o artigo 56, XII, que expõe o princípio da correção do desvio publicitário ao impor a realização da contrapropaganda.

Além dos dispositivos legais que procuram sanar irregularidades provenientes da relação de consumo e assim proteger, em diversas circunstâncias, o consumidor, devido a sua condição vulnerável frente a este tipo de relação, existe um outro ponto, não menos importante, que é a influência que a publicidade exerce sobre a mente dos consumidores a ponto de ditar comportamentos sociais, direcionando-os a adquirir bens materiais a todo instante.

\subsection{PRINCÍPIOS CONSTITUCIONAIS: LIVRE-INICIATIVA, LIBERDADE DE EXPRESSÃO E LIVRE CONCORRÊNCIA}

É inquestionável que a publicidade tem uma característica econômica e que encontra proteção constitucional na Constituição econômica, no art. 170. Entre os princípios que regem a atividade econômica podemos destacar o princípio da livre iniciativa (art.170, caput e 
parágrafo único da $\mathrm{CF}$ ), da valorização do trabalho humano, o princípio da livre concorrência (art.170, IV, CF) e o princípio da liberdade de expressão (art.5º, IX e 220 da CF).

Após a Segunda Guerra Mundial, e com o desenvolvimento da indústria e dos meios de comunicação, a publicidade passa a ser entendida como um importante instrumento para a dinâmica de mercado e para a competição entre os agentes econômicos. É através da publicidade que as empresas concorrem conquistando as fatias de mercado, convencendo os consumidores que o seu produto ou serviço é o melhor, se sobrepondo sobre as demais empresas concorrentes. Cada vez que um produto é lançado no mercado, a empresa investe nas técnicas de comunicação publicitária com o objetivo de vencer a concorrência.

Na Constituição Federal de 1988, podemos afirmar que o princípio da livre iniciativa é mais que um princípio, é fundamento da ordem econômica e da própria República, ao lado da valorização do trabalho.

A liberdade de expressão comercial está inserida na liberdade de comunicação. A Constituição de 1988 protege a liberdade de comunicação em várias oportunidades. O art. $5^{\circ}$, IX deste documento, elenca outros direitos conexos à liberdade de expressão, como a liberdade de expressão de atividade intelectual, artística e científica. Entretanto, o referido artigo não revela o significado constitucional da proteção à liberdade de comunicação, de modo que o seu conteúdo depende de outro dispositivo constitucional, do art.220.

Para André Ramos Tavares, a Constituição Federal não admite, enquanto interferência estatal, a figura da censura, de sorte que a proibição plena não se afigura como uma forma constitucionalmente admitida de interferência estatal no exercício da liberdade de expressão ou mais precisamente, da liberdade de comunicação - aqui compreendida como liberdade de comunicação commercial. (TAVARES, 2013, p.214).

Resta saber em quais situações o Estado pode limitar o exercício da liberdade de expressão comercial. Isso significa que o Estado está autorizado a estabelecer certas limitações ao exercício da liberdade de expressão, que encontra limites, não pode ser abusiva.

\section{A PUBLICIDADE E SUA RELAÇÃO COM O CONSUMISMO EM TODAS AS ETAPAS DA VIDA}

Primeiramente faz-se necessário ressaltar a vulnerabilidade do consumidor diante da Publicidade, quando esta o leva para sua teia de fantasias. O consumidor passa então a adquirir bens sem fazer nenhuma análise crítica. Destacam-se neste viés as palavras de 
Comparato: "O consumidor, vítima de sua própria incapacidade crítica e suscetibilidade emocional, dócil objeto de exploração de uma publicidade obsessora e obsidional, passa a responder ao reflexo condicionado da palavra mágica, sem resistência”. (COMPARATO, 1987, p. 197).

No mundo guiado pelo capitalismo, as pessoas tentam se adequar ao meio social em que estão inseridas. Pode-se dizer que este meio é uma verdadeira selva, onde sobrevive aquele que consegue obter o celular do momento ou o modelo de roupa que está na "modinha". Não se curvar a estes ditames significa a mais profunda solidão e segregação. A Publicidade tem uma influência bastante considerável sobre o tecido social quando o assunto é consumo.

Tudo começa bem cedo. Na infância, os meios de comunicação exibem os brinquedos mais queridos e que muitas vezes estão associados às figuras de atores ou atrizes mirins. Quem não os possui fica completamente fora das brincadeiras. Daí surge a primeira consequência: os pais são pressionados para comprarem os bens que fortemente foram divulgados e fazem parte agora da mente da criança. Surge uma obsessão, mas a pergunta é: será que realmente é necessário ceder a toda e qualquer publicidade? A primeira impressão é que se a criança não adquirir tal produto ela vai se tornar um adulto frustrado e infeliz para o resto da vida e que a culpa é toda dos pais. O problema é que adquirir o bem desejado não vai fazer cessar o estresse, pois outros produtos irão surgir e o ciclo vicioso tende a ser infinito.

No período de adolescência a publicidade também é marcante. Meninos e meninas entram na puberdade, e nesse momento, ser aceito é o que mais importa. As roupas e os acessórios são imprescindíveis para ter uma imagem "normal". A preocupação excessiva com a aparência é o principal motivo que leva a problemas de saúde como anorexia, bulimia e depressão. Para serem vistos ou respeitados, os adolescentes devem possuir aquilo que propõe a indústria de consumo. E assim, os eletrônicos estão no topo da lista de desejos. Os produtos são adquiridos não pela necessidade, mas pelo poder que eles representam no ciclo de amizades, ou seja, não basta possuir uma calça jeans que vista bem, além desta qualidade ela deve ser da marca tal e de preferência a marca deve ser bem visível para que todos percebam o valor que representa, e desta forma, o indivíduo ganha o seu lugar no mundo de valores deturpados e de mentes dominadas pela Publicidade massiva.

O assédio da publicidade ao público infanto-juvenil pode afetar dimensões variadas, que vão desde o desenvolvimento físico como a probabilidade de 
influenciar nos hábitos alimentares, passando pelo desenvolvimento cognitivo ou seja, na absorção da memorização, aprendizagem e raciocínio para o consumo - recaindo no desenvolvimento psicossocial, ou seja, na própria construção da personalidade das pessoas, com efeitos diretos nas relações sócioafetivas. (LIMA; VASCONCELOS; BRANDÃO, 2014, p. 222).

Observa-se um prazer desmedido neste tipo de consumo, atrelado novamente à dificuldade que os pais têm em dizer um "não" talvez seja por medo de frustrar seus filhos. $\mathrm{O}$ problema é que satisfazer todas as vontades e ceder a todos os tipos de publicidade pode ser bastante perigoso, pois a falta de um diálogo sobre valores, sobre educação para o consumo pode levar os adolescentes a viverem completamente fora da realidade. Vale lembrar que os jovens, por vezes, não conseguem reconhecer quais são suas verdadeiras prioridades, tornamse portanto, escravos do consumo.

As crianças e os adolescentes são alvos fáceis quando o assunto é o consumo exacerbado, pois

a sedução para todo tipo de consumo repercute no desejo, induz ao materialismo, atrapalha a educação, desgasta as relações familiares e traz incalculáveis efeitos para o desenvolvimento pessoal, em consequência, para o desenvolvimento de uma sociedade igualitária e solidária. (Ibid, p. 223).

A Constituição Federal Brasileira de 1988, reconhece explicitamente, em seu artigo 227, a garantia da dignidade a crianças, adolescentes e aos jovens (Emenda Constitucional $\mathrm{n}^{\circ}$ 65 de 2010), através do Princípio da Absoluta Prioridade do direito à dignidade.

Art. 227. É dever da família, da sociedade e do Estado assegurar à criança, ao adolescente e ao jovem, com absoluta prioridade, o direito à vida, à saúde, à alimentação, à educação, ao lazer, à profissionalização, à cultura, à dignidade, ao respeito, à liberdade e à convivência familiar e comunitária, além de colocá-los a salvo de toda forma de negligência, discriminação, exploração, violência, crueldade e opressão. (Grifo nosso).

O Princípio da Absoluta Prioridade é previsto também, no Estatuto da Criança e do Adolescente (Lei 8.069/1990), em seu artigo $4^{\circ}$., e 100, § único, inciso II, esse princípio tem por finalidade assegurar a dignidade da criança, sendo essa dignidade compreendida dentro do espectro da doutrina da proteção integral, que reconhece a condição peculiar da pessoa em desenvolvimento e busca proporcionar à criança e ao adolescente todas as condições necessárias para alcançar uma formação plena e saudável tanto física, como psíquica e emocionalmente.(ARARUNA; BARACHO, 2017, p. 48).

$\mathrm{Na}$ etapa adulta, os desejos e a busca pela satisfação ainda persistem, carros e aparelhos celulares são trocados como se fossem descartáveis. A felicidade é conquistada através da aquisição de produtos lançados pelas campanhas publicitárias. As mentes são bombardeadas por imagens a todo momento. Logicamente não se pode generalizar, existem 
pessoas que consomem com consciência, ou seja, de acordo com suas necessidades. O fato é que, a publicidade mexe com o ser humano ao manipulá-lo no sentido de implantar ideias como: ter determinado bem é ter poder, ou, "Você é aquilo que veste!".

Sobre esta necessidade de poder, relatam Schiffman e Kanuk (2015, p. 74):

A necessidade de poder refere-se ao desejo do indivíduo de controlar seu ambiente. Ela inclui a necessidade de controlar outras pessoas e vários objetos. Essa necessidade parece estar estreitamente relacionada à necessidade do ego, uma vez que muitos indivíduos experimentam maior auto estima quando exercem poder sobre objetos ou pessoas.

Nota-se que a procura por este "poder" não é exclusivamente observada nas classes sociais mais altas, ou seja, em todos os níveis sociais ocorre a procura por bens que determinam essa superioridade. Schiffman e Kanuk (2015) comentam ainda sobre algo bastante interessante, uma teoria desenvolvida por um psicólogo chamado Abraham Maslow que fala sobre a hierarquia das necessidades humanas.

A teoria de Maslow identifica cinco níveis básicos de necessidades humanas,
classificadas em ordem de importância das necessidades de nível mais baixo
(biogênicas) às necessidades de nível mais elevado (psicogênicas). A teoria
postula que os indivíduos procuram satisfazer as necessidades de baixo nível
antes que as necessidades de alto nível surjam. O nível mais baixo da
necessidade cronicamente insatisfeita que um indivíduo experimenta serve para
motivar seu comportamento. Quando essa necessidade é "plenamente" atendida,
surge uma nova (e mais elevada) necessidade que o indivíduo é motivado a
satisfazer. Quando essa necessidade é atendida, uma nova (e ainda mais elevada)
necessidade emerge, e assim por diante. (SCHIFFMAN; KANUK, 2015, p.71).

A partir desta teoria desenvolvida por Maslow, na medida em que as necessidades são satisfeitas surgem outras ainda mais fortes e capazes de fomentar o desejo de satisfazê-la. Assim, a necessidade superior tem o condão de determinar o comportamento do consumidor. A motivação para o consumo tem por base o sentimento de insatisfação.

Assim, a proposta é a busca pela felicidade através do consumo desenfreado. "A resposta à pergunta "Você é feliz? dadas por membros da sociedade de consumidores podem, de maneira legítima, ser vista como o teste maior de seu sucesso e fracasso". (BAUMAN, 2008, p. 61).

As pessoas são bombardeadas a todo instante e em todo lugar por inúmeras informações e possuem incontáveis preferências e desejos a serem alcançados. A publicidade ganha espaço na medida em que mexe com a vaidade e a eterna procura pela felicidade. Cada pessoa tem o seu próprio conceito do que seja "felicidade", possuir o melhor carro ou a joia mais cobiçada pode fazer parte de um círculo vicioso dominador que torna as pessoas vazias. São infinitas as coisas que podem satisfazer alguém, assim, as ofertas são abundantes e 
demasiadamente diversificadas para atingir o máximo de consumidores possível.

Para serem felizes e terem suas vontades satisfeitas as pessoas se tornam escravas do trabalho, ou seja, procuram obter mais dinheiro para comprar mais e mais, portanto são iludidas pelas propagandas que prometem plenitude interior através dos bens materiais. No sistema capitalista vigente, o homem é influenciado, ainda que indiretamente, a comprar produtos supérfluos completamente inúteis.

Pode-se considerar a existência de dois tipos de bens, os que são necessários e os supérfluos. Os bens necessários são aqueles sem os quais o ser humano não consegue viver, ou seja, aqueles que o homem necessita para ter saúde e uma vida tranquila. Já os bens supérfluos constituem as coisas de que os seres humanos não precisam para viver e que fazem parte de uma lista infinita. São exemplos: carros importados, relógios caros que representam poder, além de diversos artigos de luxo que provocam a ambição de muitos. Estes bens são resultantes da necessidade que as pessoas têm de satisfazer seus desejos mais superficiais, e assim, se sentirem felizes.

Outra questão relacionada ao consumismo é a progressiva evolução tecnológica que atrai principalmente os jovens que sempre buscam obter o último modelo eletrônico. Por este lado, não existe satisfação plena, pois novas invenções surgem a toda hora, então, assim quem adquire, por exemplo, um celular, em pouquíssimo tempo este se torna ultrapassado. "Os consumidores estão à espera de experiências mais envolventes em todos os aparelhos com os quais interagem.” (JAFFE, 2008, p. 249).

\section{O CONSUMISMO E SUAS CONSEQUÊNCIAS}

A publicidade é a principal ferramenta utilizada para ludibriar o consumidor, ela tem a capacidade de revelar uma fantasia que mexe com a autoestima e induz consequentemente ao consumo desmedido.

Faz-se importante relembrar a visão de Bauman (2008, p. 75-76) sobre o significado de consumo:

\footnotetext{
"Consumir", portanto, significa investir na afiliação social de si próprio, o que, numa sociedade de consumidores, traduz-se em "vendabilidade": obter qualidades para as quais já existe uma demanda de mercado, ou reciclar as que já possui, transformando-as em mercadorias para as quais a demanda pode continuar sendo criada. A maioria das mercadorias oferecidas no mercado de consumo deve sua atração e seu poder de recrutar consumidores ávidos a seu valor de investimento, seja ele genuíno ou suposto, anunciado de forma explícita ou indireta. Sua promessa de aumentar a atratividade e, por consequência, o preço de mercado dos seus compradores está escrita, em letras grandes ou
} 
pequenas, ou mesmo nas entrelinhas, nos folhetos de todos os produtos [...]O consumo é um investimento em tudo que serve para o "valor social" e a autoestima do indivíduo.

De acordo com o referido autor, não se trata apenas de satisfazer as necessidades ou os desejos; na realidade, para que os indivíduos se tornem verdadeiros membros da sociedade de consumidores tendem a ser, eles mesmos, mercadorias de consumo. "Fazer de si mesmo uma mercadoria vendável.” (BAUMAN, 2008, p.76). Observa-se que Bauman destaca a auto transformação das pessoas em mercadorias, e este é o ponto central de sua obra Vida para o Consumo. De fato, pela maneira como se entrega à vaidade e às aparências, a sociedade se torna cada vez mais escrava do consumo desenfreado. O superendividamento do consumidor tornou-se uma consequência desastrosa da pressão exercida pela publicidade somada à falta de educação financeira.

O superendividamento é um assunto bastante discutido entre renomados doutrinadores, isto se deve, principalmente, por não existir uma lei específica capaz de proteger com efetividade a figura do consumidor e que possibilite a prevenção desse fenômeno. Neste contexto, vale revelar algumas razões que impulsionam uma grande parcela da população a contrair dívidas incoerentes com sua capacidade econômica. São exemplos: o fácil acesso ao crédito e uso indevido do cartão de crédito; a promessa de juros baixos do crédito consignado; assim como, a publicidade abusiva atrelada ao consumismo típico da sociedade moderna.

O cartão de crédito é a maneira mais popular e usual de adquirir produtos ou serviços. Foi elaborado para intensificar o comércio e fazer com que mais consumidores possam ter acesso a bens de valores elevados, antes inacessíveis. Desta forma, determinados itens embora caros, podem ser obtidos por qualquer indivíduo a partir do pagamento fracionado em várias parcelas, basta que apresente uma renda mínima. Esta nova maneira de comprar ganhou proporções imensas nos anos 90 e hoje faz parte do cotidiano da maioria dos brasileiros.

No entanto, quando mal utilizado, o cartão de crédito pode se tornar um cruel inimigo do consumidor, já que o ato de dividir o preço de um objeto em doze vezes, por exemplo, faz com que a cota mensal seja pequena e fácil de ser paga, entretanto, se forem feitas sucessivas compras, a soma destas pode ultrapassar o valor da renda disponível e comprometer até mesmo o indispensável à subsistência.

Uma outra maneira de ingressar na lista dos endividados é a utilização do crédito 
consignado sem uma devida avaliação do perfil do consumidor. Empréstimo consignado é destinado principalmente aos aposentados, pensionistas e trabalhadores ativos. É uma oferta de crédito com pagamento indireto, cujo desconto é em folha, feita de maneira rápida, sem muita burocracia e não há cobrança de taxa de abertura de crédito ou qualquer outra taxa administrativa. Pode ser auferido em bancos ou financeiras, e os juros e outros encargos envolvidos são definidos de acordo com o valor contratado. O desconto máximo que incide sobre o benefício da aposentadoria é de 30\%. Trata-se de uma proposta bastante atraente direcionada aos consumidores, principalmente os idosos, com a promessa de aplicação de juros baixos e felicidade imediata já que o dinheiro vai direto para a conta instantaneamente. As propagandas usadas pelas instituições financeiras motivam esse público a procurar o crédito.

Ainda não se tem no Brasil uma legislação que verse sobre o superendividamento. $\mathrm{O}$ consumidor compra por diversos motivos, um deles é ter a sensação de ver que todo seu esforço no trabalho valeu a pena ao adquirir determinado bem. Deste modo, o produto desejado é fruto do seu labor, e, portanto, se vê merecedor de tal objeto. Ocorre que, diante da vida moderna, as ofertas são bastante tentadoras, e a publicidade pode ser sedutora o bastante para fazer com que o indivíduo gaste mais do que recebe no final do mês. Com o desejo de obter para si os bens materiais mais almejados do mercado, alguns fazem uso do crédito fácil que lhe é disponibilizado. Assim, desencadeia uma série de dívidas oriundas de uma intensa avalanche publicitária.

Na maioria dos casos, o superendividamento não se deve a uma única causa, já
que o devedor deve fazer frente a um conjunto de obrigações derivadas de
aquisição de bens e serviços de primeira necessidade, créditos hipotecários,
carros móveis etc. e, inclusive, decorrentes do abuso e incorreto uso do cartão de
crédito. Somam-se, ainda, causas não econômicas, tais como falta de informação
e educação dos consumidores, rupturas familiares, acidentes ou enfermidades
crônicas [...]. (BATTELLO, 2006, p. 211-229).

O problema do superendividamento da pessoa física por conta de dívidas de consumo reflete um problema que recai sobre todas as classes sociais. Antes de qualquer compra que por ventura comprometa a renda do mês, os indivíduos devem ter por prioridade assegurar o mínimo existencial necessário à dignidade da família.

O superendividamento ativo ocorre quando o consumidor age de forma ativa para o acúmulo de bens (essenciais ou não), gastando mais do que ganha, endividando-se, mesmo que de boa-fé; já no superendividamento passivo, o que ocorre é um imprevisto, o consumidor se endivida por motivos alheios a sua vontade. (TONETTI; CASALI, 2012, 
p. 148-154).

Este superendividamento citado é dito ativo porque é resultado da própria atitude do consumidor, ou seja, a partir de sua própria vontade de acumular produtos sem observar o seu real poder de compra, os seus limites.

Existe também o superendividamento passivo resultante não do abuso de crédito, mas que surge a partir de outros eventos alheios à vontade do indivíduo, como exemplo: o desemprego, acidentes de trabalho, reduções salariais.

Desta maneira, esteja o consumidor tomado por um superendividamento ativo ou passivo, os elementos materiais necessários à manutenção de sua própria existência ou de terceiros dependentes devem estar em primeiro plano para que a dignidade seja preservada.

Então, importante se fazem as palavras de Giancoli (2008, p. 123): "a correção da assimetria de uma ou diversas relações jurídicas contraídas pelo consumidor, em razão da existência de um conjunto de dívidas estruturais ajustadas de boa-fé, capazes de ameaçar ou lesionar sua dignidade pessoal".

Os reflexos do superendividamento na vida dos consumidores é extremamente devastador, pois os juros, as dívidas adquiridas os tornam desestimulados e fracassados diante deste cenário. As contas do mês não fecham e isto pode comprometer o bem-estar da família. Então, o superendividamento é estarrecedor, pois as empresas, quando vão contratar, verificam se o nome do candidato a funcionário está presente na lista do sistema SPC e SERASA. Estando neste rol, é tido como indivíduo que não tem competência nem para gerir o seu próprio dinheiro. São pessoas frágeis que necessitam reorganizar sua vida financeira, já que caíram no mundo fantástico apresentado pela publicidade. Neste sentido apresenta Bolade (2012, p. 180-209):

A publicidade nesse contexto se insere como meio, produzindo uma mudança conceitual na amplitude do crédito, cujo poder é superior ao do consumo, oferecendo ao consumidor mais do que bens ou serviços, conferindo status; num primeiro momento, os consumidores que são mais facilmente percebidos e vulneráveis são os que não possuem condições de defesa contra os abusos da publicidade, $\log$, não têm condições de exercer verdadeiramente a autonomia da vontade.

$\mathrm{Na}$ realidade o consumidor deve estar atento e diferenciar a necessidade real da necessidade aparente. Esta é fruto da vaidade e do desperdício. Nesta esteira, faz-se extremamente importante a educação financeira, saber balancear a renda e os gastos. De acordo com Jacob e Hudson (2000, p.8), a educação financeira pode assim ser entendida:

[...] o termo "financeira", aplica-se a uma vasta escala de atividades relacionadas ao dinheiro na nossa vida diária, desde o controle do cheque até o 
gerenciamento de um cartão de crédito, desde a preparação de um orçamento mensal até a tomada de um empréstimo, compra de um seguro, ou um investimento. Enquanto que educação implica o conhecimento de termos, práticas, direitos, normas sociais, e atitudes necessárias ao entendimento e funcionamento destas tarefas financeiras vitais. Isto também inclui o fato de ser capaz de ler e aplicar habilidades matemáticas básicas para fazer escolhas financeiras sábias.

Além do superendividamento, o consumismo impulsionado pela publicidade fascinante causa ainda transtornos interpessoais. Posto que afeta as relações sociais na medida em que pessoas são excluídas do meio social por não possuírem determinados bens, seja roupa, carro ou celular de última geração. Pessoas são segregadas por não possuírem esses objetos valiosos, e portanto, são desvalorizadas.

A sociedade de consumidores discrimina os pobres, como menciona Bauman (2008, p. 160-161):

Os pobres da sociedade de consumidores são inúteis. Membros decentes e normais da sociedade - consumidores autênticos - nada desejam nem esperam deles. Ninguém (e, o que é mais importante, ninguém que de fato importe, que fale e seja ouvido) precisa deles. Para eles, tolerância zero. A sociedade ficaria melhor se os pobres queimassem seus barracos e se permitissem queimar junto com eles - ou apenas sumissem. Sem eles o mundo seria mais afetuoso e agradável de viver. Os pobres são desnecessários, e, portanto, indesejados.

$\mathrm{O}$ autor ainda relata que em uma sociedade com valores invertidos, o dinheiro, o poder de compra, está acima de qualquer outra coisa. Os sentimentos de solidariedade e amor ao próximo são deixados de lado; é como se os pobres fossem a parte suja da comunidade humana, e essa "sujeira" deve ser escondida debaixo do tapete. Representam um incômodo ao tecido social, portanto, deve-se "apagar um ponto sujo na tela agradavelmente pura de um mundo ordenado e de uma sociedade normal" (BAUMAN, 2008, p. 162). Além disso, os pobres são os primeiros suspeitos quando acontece qualquer desordem, são os "elementos" procurados pela polícia, o que demonstra claramente a seletividade do sistema criminal.

Um ponto também importante é considerar o consumismo como uma verdadeira alienação, um vício que provoca distúrbios como a Oneomania, caracterizada pela compulsão por compras. Portanto, o consumismo exagerado que leva ao superendividamento hoje já é encarado, por alguns especialistas, como uma patologia.

Especialistas enumeraram alguns comportamentos que sinalizam para o começo da doença do consumo, a Oneomania:

Quando está triste ou frustrado sempre busca comprar algo;b) Tem preocupação excessiva em comprar;c) Acaba sempre gastando mais dinheiro e mais tempo do que o planejado;d) Tem problemas familiares e desgaste em suas relações sociais por conta dos gastos excessivos;e) Tem dívidas que superam o valor que pode pagar;f) Sempre está procurando maneiras de conseguir dinheiro para 
cobrir o rombo da conta bancária;g) Compra itens desnecessários ou em quantidades exageradas; $h$ ) Sempre se arrepende logo após as compras e sente-se frustrado com isto;i) Toma empréstimo para cobrir os gastos; j) Mente, omite e esconde as compras excessivas e também as dívidas. ${ }^{3}$

Assim como qualquer outro tipo de vício, a Oneomania surge para diminuir as tensões próprias da vida moderna, como se o ato de comprar fosse a única saída para minimizar o estresse ou a depressão.

A publicidade acaba moldando comportamentos sociais através do consumismo. Algumas das consequências foram aqui relatadas como: a autotransformação das pessoas em mercadorias (ideia elencada por Bauman); o superendividamento; segregação social e Oneomania (compulsão por acúmulo de bens). Mas, deve-se lembrar que, além dessas, existem muitas outras consequências advindas desse mundo envolvente e alienante que a publicidade revela.

\section{CONSIDERAÇÕES FINAIS}

A publicidade é uma ferramenta excessivamente utilizada pelas empresas na divulgação de diversos tipos de produtos que rodeiam o consumidor que acaba adquirindo-os sem haver necessidade. O fato é que a publicidade estimula o consumo, o desejo pelo "novo", a promessa da felicidade e de realização pessoal. O consumismo surge pela vontade de comprar mais e mais bens supervalorizados pela publicidade, e, desta forma, as pessoas são manipuladas a ponto de mudar seus comportamentos no meio social.

Neste diapasão, pode-se dizer que o consumo exagerado, atrelado aos infinitos desejos materiais, é observado em todas as etapas da vida humana. A partir da infância, o mundo de fantasias criado pela publicidade é bastante atraente, por isto, é importante que os pais saibam agir, ensinar aos seus filhos a diferença entre desejo e necessidade, caso contrário, estarão contribuindo para que as futuras gerações sigam um modelo consumista. Neste sentido, a educação financeira se faz essencial desde o início do processo de formação, orientação.

Sérios problemas são oriundos da publicidade, alguns são destaques no presente trabalho: as pessoas se fazerem mercadorias; o superendividamento do consumidor; isolamento social dos pobres e a compulsão por compras como uma patologia chamada Oneomania. Todas essas consequências do consumo exacerbado têm íntima ligação com o

\footnotetext{
${ }^{3}$ Disponível em: <http://www.minutopsicologia.com.br/postagens/2015/05/15/oneomania-a-doenca-doconsumismo/>. Acesso em: 06 Set. 2017.
} 
fenômeno da publicidade, é como se este fosse um vírus letal para a sociedade e cujo poder de destruição é tão avassalador que compromete a dignidade humana.

O superendividamento termina por afetar essa dignidade na medida em que há um comprometimento não apenas do indivíduo como consumidor, mas como pessoa humana que acaba sendo marginalizada em seu próprio meio social.

Assim, com a insolvência civil, o consumidor, que passa a ser apenas devedor, tem seu nome negativado, inserido no cadastro de proteção ao crédito, comprometendo muitas vezes o seu patrimônio, a ponto de colocar em risco o mínimo existencial, ou seja, os bens necessários à satisfação de suas próprias necessidades básicas ferindo a dignidade.

Por todo o exposto, a publicidade como mecanismo propulsor do consumismo, torna as pessoas escravas de um verdadeiro círculo vicioso, e pode-se concluir que o processo de educação financeira é um caminho a ser trilhado a fim de que o mesmo possa não apenas orientar, mas formar um cidadão mais consciente de sua condição social, de suas economias.

A partir de uma educação voltada para a prática de um consumo consciente, caracterizado pelo discernimento do que é realmente necessário, a sociedade pode ser livre, pois em nenhum momento a felicidade deve ser condicionada ao consumo de bens materiais, tendo em vista que a vida se transformaria num eterno vazio que precisaria ser preenchido constantemente pelo consumo, em sua maioria, de bens supérfluos.

\section{REFERÊNCIAS}

ARARUNA, S.P.; BARACHO, H.U. A Publicidade dirigida à criança e ao adolescente é legal? Revista de Direito, Globalização e Responsabilidade nas Relações de Consumo, Brasília, v.3, n.1, p.44-62, Jan/Jun, 2017.

BATTELLO, S. J. A (In)justiça dos endividados brasileiros: uma análise evolutiva. In: MARQUES, C. L.; CAVALLAZZI, R. L.(Org.). Direitos do Consumidor Endividado: Superendividamento e crédito. São Paulo: Revista dos Tribunais, 2006.

BAUMAN, Z. Vida para Consumo: a transformação das pessoas em mercadoria. Rio de Janeiro: Zahar, 2008.

BOLADE, G. A. O Superendividamento do Consumidor como um Problema Jurídico-Social. Revista ANIMA, Curitiba, PR, ano 3, n. 8, jul. 2012.

BRASIL. Constituição da República Federativa do Brasil (1988). In: BRASIL. Vade Mecum Acadêmico de Direito. 4 ed. São Paulo: Rideel, 2007. 
. Lei 8.078, de 11 de setembro de 1990. Código de Defesa do Consumidor. In:

BRASIL. Vade Mecum Acadêmico de Direito. 4 ed. São Paulo : Rideel, 2007.

DIAS, L. A. L. de M. Publicidade e Direito. 3 ed. atual. e reform. São Paulo: Saraiva, 2018

COMPARATO, F. K. A proteção ao Consumidor na Constituição Brasileira de 1988. Revista de Direito Mercantil, Industrial, Econômico e Financeiro, São Paulo, v. 80, 1987.

DE ALMEIDA, J. B. A proteção jurídica do consumidor. 6. ed. São Paulo:Saraiva,2008.

DE CARVALHO JUNIOR, O. Da Oferta e da Publicidade: abusos contra o consumidor In: Reflexões críticas de Direito do Consumidor: estudos em homenagem ao professor Fernando Vasconcelos. João Pessoa: Ideia, 2013.

DOS SANTOS, P. T.; CASALI, E. C. O Superendividamento do Consumidor. Revista Linhas Jurídicas, Votuporanga, SP, v. 4, n. 4, jun. 2012.

GIANCOLI, B. P. O superendividamento do consumidor como hipótese de revisão dos contratos de crédito. Porto Alegre: Editora Verbo Jurídico, 2008.

JACOB, K.; HUDSON, S.; BUSH, M. Tools for survival: An analysis of financial literacy programs fo lowerincome families. Chicago: Woodstok Institute, 2000.

JAFFE, J. O Declínio da Mídia de Massa - Por que os comerciais de TV de 30 segundos estão com os dias contados. São Paulo: M.Books do Brasil Editora, 2008.

LIMA, W.; VASCONCELOS, F.; BRANDÃO, F. Proteção da Criança e do Adolescente frente ao Assédio da Publicidade. In: VASCONCELOS F.; GUERRA G.

RAMOS A, et. al (Org.). Proteção Jurídica do Consumidor em Perspectiva Transversal. João Pessoa: AREPB, 2014.

SCHIFFMAN, L. G.; KANUK, L. L. Comportamento do consumidor. 9 ed. Rio de Janeiro: LTC, 2015.

TAVARES, A. R. Direito Constitucional da Empresa. São Paulo: Método, 2013 